\title{
Single-Phase Synchronization for Traction Active Rectifier
}

\author{
Vojtech Blahnik, Jakub Talla \\ Regional Innovation Centre for Electrical Engineering \\ University of West Bohemia \\ Pilsen, Czech Republic \\ lucke@rice.zcu.cz, talic@rice.zcu.cz
}

\begin{abstract}
This paper introduces the advanced synchronization method second order general integrator phase locked loop modified especially for voltage synchronization exclusively for traction active rectifier. Designed synchronization is characterized by resistance to interfaces and especially quick response to frequency fluctuations. The behavior of designed synchronization method was analyzed by simulations tests and the final synchronization adjustment was suggested.
\end{abstract}

Keywords- SOGI-PLL; active rectifier; single-phase; synchronization

\section{INTRODUCTION}

The general topology of locomotive or suburban unit is depicted in Figure 1. The electrical equipment is composed of input transformer, single-phase voltage-source active rectifier, three-phase traction inverter and traction motor. The active rectifier provides precise and fast control of dc-link voltage, proper current limitation and ensuring of harmonic trolley wire current. To ensure those active rectifier essential characteristics must be used accurate and rapid voltage synchronization method. We are talking about single-phase synchronization method, some advanced synchronization methods are presented in [1] - [10]. The main problems of single-phase voltage synchronization which are possible must be suppressed. We suppose the problem of interference during voltage measurement. Another problematic condition can be rapid changes in voltage magnitude (step changes may occur). There may be a small change in frequency (assumption is $\pm 2 \mathrm{~Hz}$ ), this is a slow change. Step changes in the position of the voltage vector are not expected.

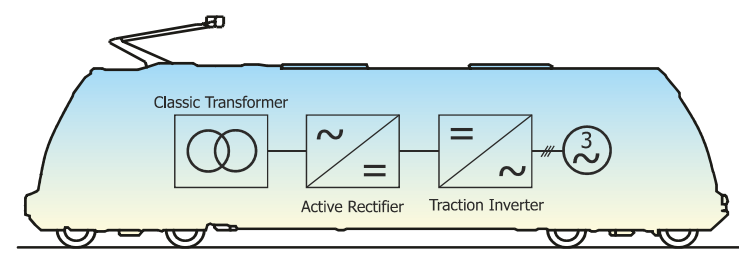

Figure 1. General topology of classic locomotive or suburban unit

\section{Single-Phase Voltage SynChronization}

In the case of the three-phase supply systems are known robust synchronization voltage method. A very popular method is Second Order General Integrator Phase Locked Loop (SOGI-PLL), because there is measured only grid voltage and we obtain three information about the position of the voltage vector $\vartheta$, magnitude of the voltage vector $\mathrm{U}_{\mathrm{m}}$, and fundamental frequency of voltage $\omega$. Advantages of SOGI-PLL are simple implementation, fast response and especially sufficient resistance against distorted signal.

The block diagram of proposed single-phase SOGI-PLL synchronization is shown in Figure 2. The interference resistance of synchronization is provided by integral blocks with output signals $\mathrm{u}_{\alpha}, \mathrm{u}_{\beta}$. It is based on the transfer function PI controller (1) and suitable wiring connection is possible use imaginary parts of voltage in stationary reference frame $\left(u_{\beta}\right)$. These signal $u_{\beta}$ and real part of voltage in stationary reference frame $\left(\mathrm{u}_{\alpha}\right)$ are used for calculation of voltage magnitude $U_{m}$ according to equation (2). The proportional controller with gain $\mathrm{K}_{\mathrm{SOGI}}$ has impact to PLL signals stabilization time. At the output part is used conventional PLL structure with Park's transformation where the signals $\left(\mathrm{u}_{\alpha}, \mathrm{u}_{\beta}\right)$ transform from stationary reference frame to d,q rotating system, by equation (3) and (4). The better representation of this transformation is illustrated at vector diagram in Figure 3.

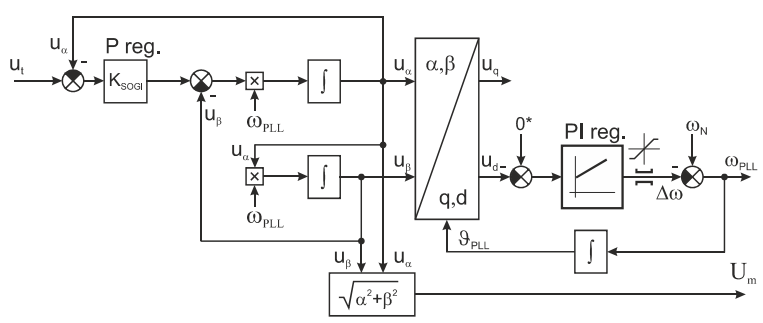

Figure 2. Single-phase SOGI-PLL synchronization 


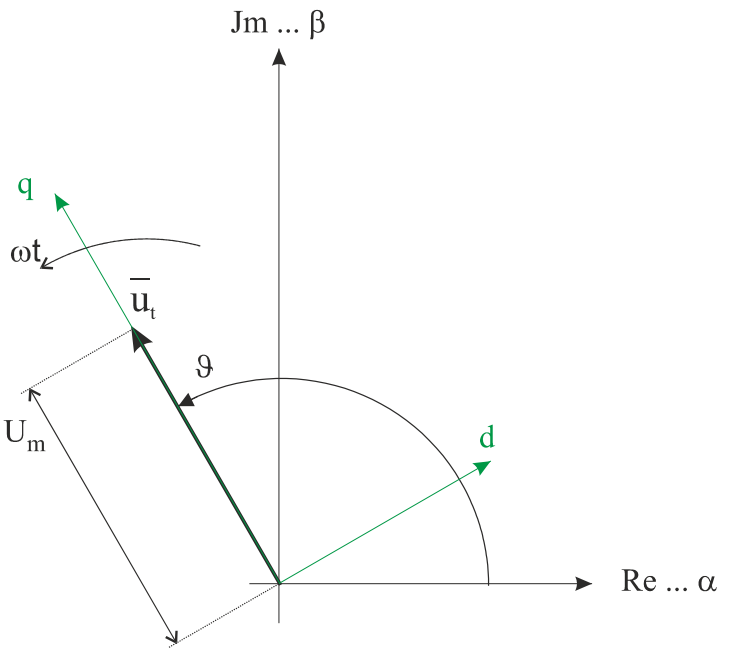

Figure 3. Vector diagram for single-phase voltage synchronization

$$
\begin{gathered}
F(s)=K_{P} \cdot \frac{1+\frac{K_{P}}{K_{I}} \cdot s}{\frac{K_{P}}{K_{I}} \cdot s} \\
U_{m}=\sqrt{u_{\alpha}^{2}+u_{\beta}^{2}} \\
u_{q}=u_{\alpha} \cdot \cos \left(\vartheta_{P L L}\right)+u_{\beta} \cdot \sin \left(\vartheta_{P L L}\right) \\
u_{d}=u_{\beta} \cdot \cos \left(\vartheta_{P L L}\right)+u_{\alpha} \cdot \sin \left(\vartheta_{P L L}\right)
\end{gathered}
$$

\section{Single-Phase SOGI-PLL Simulation Tests}

The behavior of single-phase voltage synchronization is tested on developed simulation model. This simulation model is realized in $\mathrm{C}$ language. The simulation step is chosen with regard to the accuracy of simulation $\mathrm{h}=1^{-7} \mathrm{~s}$ and discrete sampling step is selected with regard to real implementation at DSP $\left(\mathrm{T}_{\mathrm{vz}}=50 \mu \mathrm{s}\right.$, that is also used as relevant transport delay).

\section{A. Synchronization hooking}

The single-phase SOGI-PLL voltage synchronization was first tested at the starting hooking. In this case, there was only a short change at the output frequency $\omega_{\text {PLL. }}$. The stabilization time is shorter than $0.4 \mathrm{~s}$ in detail Figure 4.

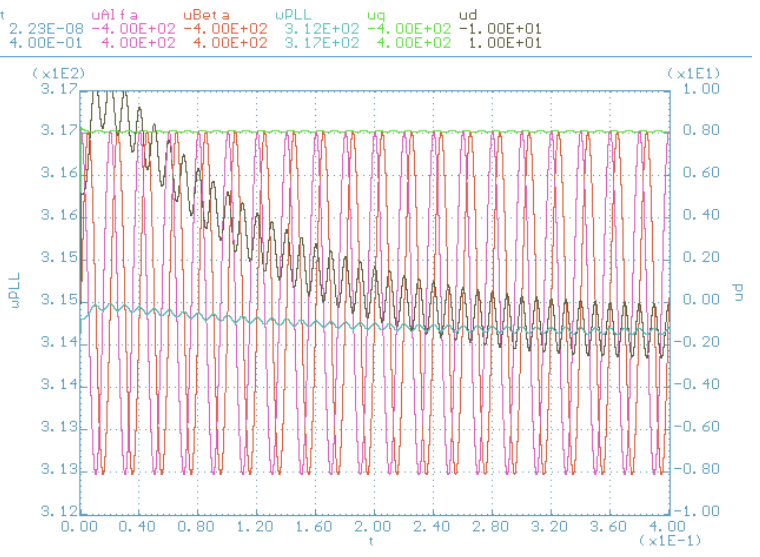

Figure 4. SOGI-PLL synchronization hooking $\mathrm{u}_{\alpha}$ - real votage component $(80 \mathrm{~V} / \mathrm{div}), \mathrm{u}_{\beta}$ - imaginary voltage component $(80 \mathrm{~V} / \mathrm{div}), \omega_{\mathrm{PLL}}-\mathrm{PLL}$ angular velocity $\left(0.5 \mathrm{rad} . \mathrm{s}^{-1} / \mathrm{div}\right)$ uq -active voltage component ( $80 \mathrm{~V} /$ div), ud - reactive voltage component (2V/dílek)

\section{B. Voltage magnitude changes}

The problematic condition for voltage synchronization can be rapid changes in voltage magnitude. This types of changes are caused by rapid load up or load down of supply network. The response of tested synchronization is very fast as documented in Figure 5. limiter value is set to $\pm 2 \mathrm{~Hz}\left( \pm 12.57 \mathrm{rad} \mathrm{s}^{-1}\right)$, because the maximal range of supply voltage frequency is expected from $48 \mathrm{~Hz}$ to $52 \mathrm{~Hz}$. The maximum rate of change in voltage frequency is expected about $1 \mathrm{~Hz} / \mathrm{s}$.

The resulting angular velocity is $\omega_{\mathrm{PLL}}$, that we get sum of correction signal $\Delta \omega$ and nominal value $\omega_{\mathrm{N}}$. The position of voltage vector ( $\left.\vartheta_{\mathrm{PLL}}\right)$ is calculated by using of integral block for the signal $\omega_{\text {PLL }}$. 


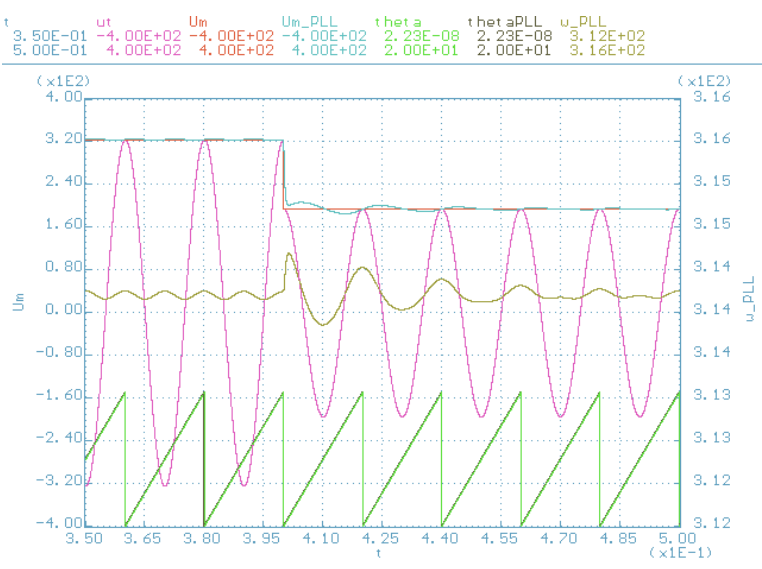

Figure 5. SOGI-PLL synchronization response to voltage change $\mathrm{u}_{\mathrm{t}}$ - voltage input signal $(80 \mathrm{~V} / \mathrm{div}), \mathrm{U}_{\mathrm{m}}$ - magnitude of input voltage $(80 \mathrm{~V} /$ div $), U_{m}$ PLL - PLL voltage magnitude $(80 \mathrm{~V} /$ div $)$, theta - position of input voltage ( $2 \mathrm{rad} / \mathrm{div})$, theta $\mathrm{PLL}_{\mathrm{L}}$ - PLL voltage position $(2 \mathrm{rad} / \mathrm{div}), \omega_{\mathrm{PLL}}$ - reactive voltage component $\left(0.4 \mathrm{rad} . \mathrm{s}^{-1} / \mathrm{div}\right)$

\section{Voltage frequency changes}

The very unpleasant condition for voltage synchronization can be changes in voltage frequency. This types of changes are also caused by high load up or load down at the supply network. The response of tested synchronization is satisfactory for step change as a shown in Figure 6. The stabilization time is shorter than $1 \mathrm{~s}$ during change of voltage frequency from $50 \mathrm{~Hz}$ to $48 \mathrm{~Hz}$.

The relevant change of voltage frequency is shown in Figure 7. This frequency change is from $50 \mathrm{~Hz}$ to $48 \mathrm{~Hz}$ with rate $1 \mathrm{~Hz} / \mathrm{s}$.

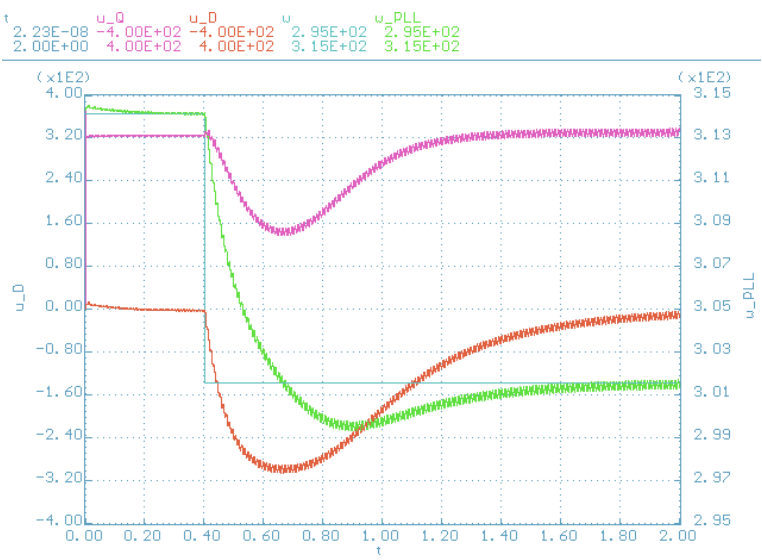

Figure 6. SOGI-PLL synchronization response to frequency change (step frequency change from $50 \mathrm{~Hz}$ to $48 \mathrm{~Hz}$ ) $\mathrm{u}_{\mathrm{Q}}$-active voltage component $(80 \mathrm{~V} / \mathrm{div}), \mathrm{u}_{\mathrm{D}}$-reactive voltage component ( $80 \mathrm{~V} / \mathrm{div}), \omega-$ input voltage angular velocity $(2 \mathrm{rad} . \mathrm{s}$ $1 / \mathrm{div}), \omega_{\mathrm{PLL}}-\mathrm{PLL}$ angular velocity $\left(2 \mathrm{rad} . \mathrm{s}^{-1} / \mathrm{div}\right)$

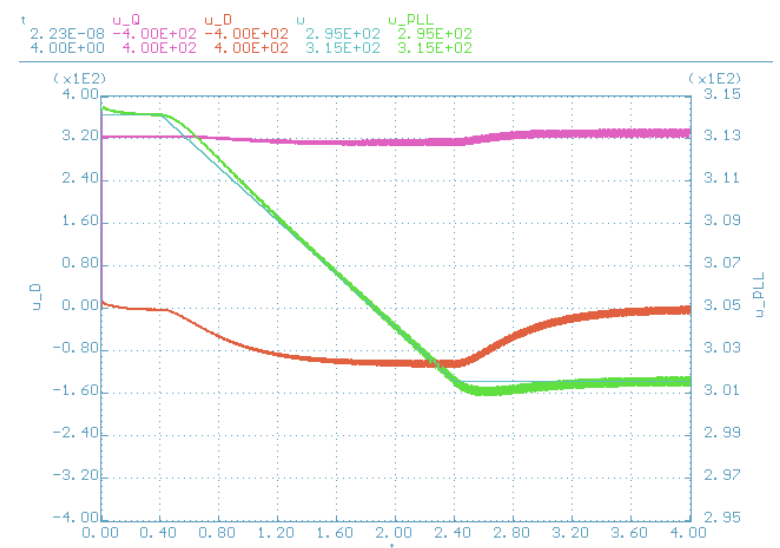

Figure 7. SOGI-PLL synchronization response to frequency change (rapid frequency change from $50 \mathrm{~Hz}$ to $48 \mathrm{~Hz}$ ) $\mathrm{u}_{\mathrm{Q}}$-active voltage component $(80 \mathrm{~V} / \mathrm{div}), \mathrm{u}_{\mathrm{D}}$-reactive voltage component ( $80 \mathrm{~V} / \mathrm{div}), \omega-$ input voltage angular velocity (2rad.s $1 / \mathrm{div}), \omega_{\mathrm{PLL}}-\mathrm{PLL}$ angular velocity $\left(2 \mathrm{rad} . \mathrm{s}^{-1} / \mathrm{div}\right)$

\section{Voltage position changes}

The changes in the position of the voltage vector are very problematic for PLL types of synchronization. In this case the SOGI-PLL voltage synchronization was tested for step change in position with value $\pi / 2$. This test result is documented in Figure 8. and in detail Figure 9. The stabilization time is shorter than $0.5 \mathrm{~s}$, but this type of change is not expected.

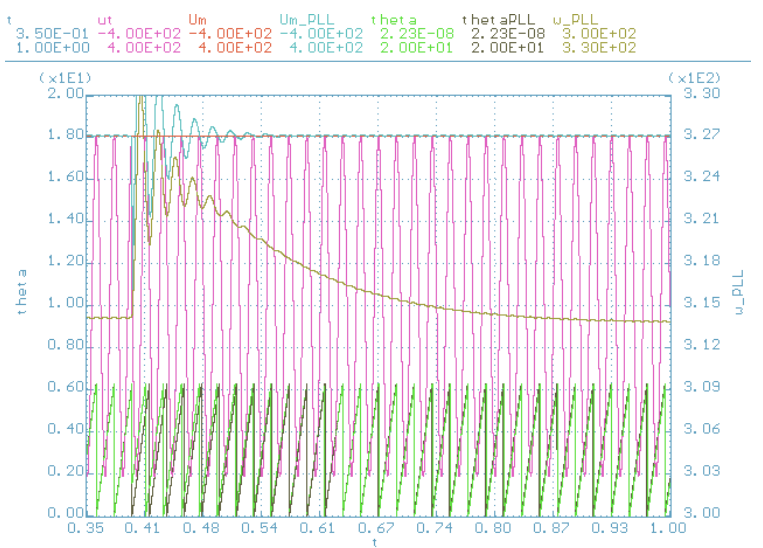

Figure 8. SOGI-PLL synchronization response to voltage position change (step change with value $\pi / 2$ )

$\mathrm{u}_{\mathrm{t}}$ - voltage input signal $(80 \mathrm{~V} / \mathrm{div}), \mathrm{U}_{\mathrm{m}}-$ magnitude of input voltage $(80 \mathrm{~V} / \mathrm{div}), \mathrm{U}_{\mathrm{m} \text { PLL }}-$ PLL voltage magnitude $(80 \mathrm{~V} / \mathrm{div})$, theta - position of input voltage ( $2 \mathrm{rad} / \mathrm{div})$, thetapLL - PLL voltage position $(2 \mathrm{rad} / \mathrm{div}), \omega_{\mathrm{PLL}}$ - reactive voltage component $\left(0.4 \mathrm{rad} . \mathrm{s}^{-1} / \mathrm{div}\right)$ 


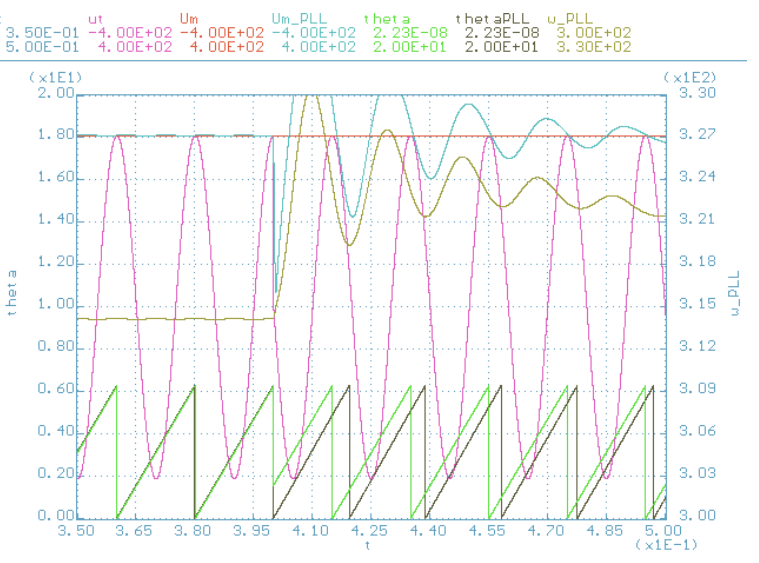

Figure 9. SOGI-PLL synchronization response to voltage position change in detail (step change with value $\pi / 2$ )

$\mathrm{u}_{\mathrm{t}}-$ voltage input signal $(80 \mathrm{~V} / \mathrm{div}), \mathrm{U}_{\mathrm{m}}-$ magnitude of input voltage $(80 \mathrm{~V} / \mathrm{div}), \mathrm{U}_{\mathrm{m} \_ \text {PLL }}-\mathrm{PLL}$ voltage magnitude $(80 \mathrm{~V} / \mathrm{div})$, theta - position of input voltage ( $2 \mathrm{rad} / \mathrm{div})$, theta $\mathrm{PLL}_{\mathrm{PL}}$ PL voltage position ( $2 \mathrm{rad} / \mathrm{div}), \omega_{\mathrm{PLL}}$ - reactive voltage component $\left(0.4 \mathrm{rad} . \mathrm{s}^{-1} / \mathrm{div}\right)$

\section{PARAMETRY SYNCHRONIZACE}

The structure of presented single-phase SOGI-PLL voltage synchronization obtain two controllers. The first controller is proportional (P reg.) with gain $\mathrm{K}_{\text {SOGI }}$. This gain has impact to PLL signals stabilization time and also to interference resistance. The second controller is PI (PI reg.) with $K_{p}$ gain and $T_{i}$ integration time constant. These constants affect the tracking speed of reactive component $\left(\mathrm{u}_{\mathrm{d}}\right)$ and therefore voltage frequency tracking. The final controller setting was done empirically and found values are shown in TABLE I.

TABLE I. SINGLE-PHASE SOGI-PLL SYNCHRONIZATION SETTINGS

\begin{tabular}{|l|l|c|c|}
\hline $\begin{array}{c}\text { Controller } \\
\text { label }\end{array}$ & \multicolumn{1}{|c|}{$\begin{array}{c}\text { Controller } \\
\text { type }\end{array}$} & $\begin{array}{c}\text { Proportional } \\
\text { gain }\end{array}$ & $\begin{array}{c}\text { Integration } \\
\text { time } \\
\text { constant }\end{array}$ \\
\hline P reg. & proportional & $\mathrm{K}_{\mathrm{SOGI}}=1$ & \\
\hline PI reg. & $\begin{array}{l}\text { Proportional- } \\
\text { Integration }\end{array}$ & $\mathrm{K}_{\mathrm{p}}=0.03$ & $\mathrm{~T}_{\mathrm{i}}=0.5 \mathrm{~s}$ \\
\hline
\end{tabular}

\section{CONSLUSIONS}

This paper presented single-phase voltage synchronization based on SOGI-PLL structure. This type of voltage synchronization is very good solution for traction active rectifier, for example [11] - [13]. This synchronization is also suitable for use in advanced PV power station of low-power or for special single-phase power supply source [14] - [15]. The main advantage of proposed synchronization algorithm is resistance against interference and unpredictable changes in the supply voltage (magnitude and frequency). This fact was shown by the simulation behavior of SOGI-PLL.

\section{ACKNOWLEDGMENT}

This research has been supported by the Ministry of Education, Youth and Sports of the Czech Republic under the RICE - New Technologies and Concepts for Smart Industrial Systems, project No. LO1607. and project No. SGS-2015-038.

\section{REFERENCES}

[1] F. D. Freijedo, J. Doval-Gandoy, O. Lopez and J. Cabaleiro, "Robust Phase Locked Loops Optimized for DSP Implementation," Power Quality Applications, Industrial Electronics, 2008. IECON 2008 34th Annual Conference of IEEE on 10-13 Nov 2008.

[2] F. Blaabjerg, R. Teodorescu, M. Liserre and A. V. Timbus, "Overview of control and grid synchronization for distributed power generation systemsc," IEEE Trans. On Ind. Electronics, vol.53, pp. 1398-1409, Oct. 2006.

[3] M. Ciobotaru, R. Teodorescu and F. Blaabjerg, "A new single-phase PLL structure based on second order generalized integrator," IEEE Power Electron Spec. Conf. (PESC 06), pp.1-7, June 2006

[4] P. Rodriguez, R. Teodorescu, I. Candela, A. V. Timbus, M. Liserre and F. Blaabjerg, "New Positive-sequence Voltage Detector for Grid Synchronization of Power Converters under Faulty Grid Conditions," Power Electronics Specialists Conference, 2006. PESC '06. 37th IEEE, 2006.

[5] M. K. Ghartemani and M. R. Iravani, "A method for synchronization of power electronic converters in polluted and variable-frequency environments, " IEEE Trans. Power Systems, Vol. 19, No.3, August 2004.

[6] M. Karimi-Ghartemani, M. R. Iravani, "A New Phase-Locked Loop (PLL) System, ” IEEE Trans. on Ind. Elect., vol.51, n.2, April 2004.

[7] T. Komrska, D. Janík and Z. Peroutka, "Synchronization of grid-connected converters for single-phase systems, " Power Electronics and Applications (EPE), 2013 15th European Conference on , pp. 1-8., Lille, 2013.

[8] T. Besselmann, A. Mester and D. Dujic, "Power Electronic Traction Transformer: Efficiency Improvements Under LightLoad Conditions," Power Electronics, IEEE Transactions on , vol.29, no.8, pp.3971-3981, Aug. 2014.

[9] Siyu Gao and M. Barnes, "Phase-locked loop for AC systems: Analyses and comparisons," Power Electronics, Machines and Drives (PEMD 2012), 6th IET International Conference on, pp.1-6, 27-29 March 2012.

[10] A. Kulkarni and V. John, "A novel design method for SOGIPLL for minimum settling time and low unit vector distortion," Industrial Electronics Society, IECON 2013 39th Annual Conference of the IEEE, pp.274-279, 10-13 Nov. 2013.

[11] V. Blahnik, Z. Peroutka and J.Talla, "Advanced control strategy for single-phase voltage-source active rectifier with low harmonic emission," Journal of Electrical Engineering, vol.65, no.2, pp. 121-124, 2014.

[12] Chuanhong Zhao, D. Dujic, A. Mester, J. K. Steinke, M. Weiss, S. Lewdeni-Schmid, T. Chaudhuri and P. Stefanutti, "Power Electronic Traction Transformer-Medium Voltage Prototype," IEEE Trans. Ind. Electron., vol.61, no.7, pp.32573268, July 2014.

[13] M. Glinka and R. Marquardt, "A new AC/AC multilevel converter family," IEEE Trans. Ind. Electron., vol.52, no.3, pp.662,669, June 2005.

[14] M. Pastor and J. Dudrik, "Predictive Control of GridConnected Multilevel Inverter with Output LCL Filter," Electronics and Electrical Engineering, vol. 21, no.3, pp. 10$15,2015$.

[15] V. Blahnik, J. Talla and Z. Peroutka, "Current source based on H-bridge inverter with output LCL filter," Journal of Electrical Engineering, vol.66, no.5, pp. 287-291, 2015. 